\title{
Searching for Sobriety: How Persons with Severe Mental Illness Experience Abstaining from Substance Use
}

\author{
Henning Pettersen ${ }^{1,2^{*}}$, Torleif Ruud ${ }^{3,4}$, Edle Ravndal ${ }^{2}$ and Anne Landheim ${ }^{1}$ \\ ${ }^{1}$ National Centre for Dual Diagnosis, Innlandet Hospital Trust, N-2381 Brumunddal, Norway \\ ${ }^{2}$ Norwegian Centre for Addiction Research, University of Oslo, N-0407 Oslo, Norway \\ ${ }^{3}$ Akershus University Hospital, Division Mental Health Services, N-1478 Lørenskog, Norway \\ ${ }^{4}$ University of Oslo, Institute of Clinical Medicine, P.O. Box 1171, N-0318 Oslo, Norway
}

*Corresponding author: Henning Pettersen, National Centre for Dual Diagnosis, Innlandet Hospital Trust, P.O. Box 104, N-2381 Brumunddal, Norway, 60175-270. Tel.: 0047 95235497; Fax: +55 853267 3867; E-mail: Henning.Pettersen@medisin.uio.no

Received date: May 23, 2014, Accepted date: Sep 15, 2014, Publication date: Sep 18, 2014

Copyright: (c) 2014 Pettersen $\mathrm{H}$, et al. This is an open-access article distributed under the terms of the Creative Commons Attribution License, which permits unrestricted use, distribution, and reproduction in any medium, provided the original author and source are credited.

\begin{abstract}
Individuals diagnosed with severe mental illness (SMI) are more vulnerable to substances than are other people. Many people with SMI tend to attain full remission of their substance use, but others relapse frequently. There is more research on the reasons for substance use than on the reasons for abstaining among these individuals. Information from the latter may contribute to a better understanding of how individuals with SMI experience abstaining from substance use. Objective: The aim of this explorative study was to examine experiences of abstaining from substances of persons diagnosed with SMI. We examined both the reasons given and the requirements and strategies used when abstaining.
\end{abstract}

Methods: A qualitative study with semi-structured interviews was conducted, and a descriptive and explorative design was applied. This study included a purposeful sample of 11 patients with SMI and substance use being treated by assertive community treatment teams.

Results: The main reasons for quitting substance use were social relationships and meaningful activities. The stated requirements and strategies used in the search for sobriety were detachment towards people and places, positive thinking, controlling feelings and emotions, and fear of dependency.

Conclusion: Our results are consistent with those from other qualitative studies on the importance of social relationships and meaningful activities as expressed reasons for abstaining. The strategy of actively avoiding a former adverse milieu to reach sobriety is consistent with findings from one similar study. The strategies of fear of adverse consequences, positive thinking, and controlling feelings and emotions found in the present study have not been reported by other qualitative studies.

Keywords: $\quad$ Abstaining from substances; Psychotic disorder; Assertive community treatment; Patient experiences; Qualitative study

\section{Introduction}

Both epidemiological [1,2] and clinical [3,4] studies have reported that individuals diagnosed with severe mental illness (SMI) are more prone to substance use than are people without SMI. Individuals diagnosed with SMI are also at greater risk of hospitalization, homelessness and suicide [5], and experience more adversity in different arenas throughout life [6,7]. Some studies have indicated that persons with SMI are more vulnerable to substances than are other people $[8,9]$, whereas other studies have not found this relationship [10]. The substances used most frequently by persons with SMI are alcohol, followed by cannabis and stimulants; sedatives and hallucinogens are used less frequently [5,11,12]. Amphetamine use is greater in persons with psychotic disorders compared with the general population $[13,14]$. Studies have shown that both cannabis $[15,16]$ and, to a greater extent, amphetamines $[17,18]$ can provoke psychosis. Because individuals do not use cannabis or amphetamines alone, but use them in combination with several other substances, examining the effects of the use of a specific substance on mental illness is a particular challenge. One review showed that substance use has adverse longterm effects on cognitive functions in persons with SMI. Alcohol use seems to be the most negative, whereas cannabis use has little influence on cognitive functions [19].

Many people with SMI tend to attain full remission of their substance use, whereas others relapse frequently [20,21]. Research from different treatment settings indicate that 30 per cent of those with less severe mental illness and heavy substance use attain sustained remission[22], whereas up to 60 per cent of those with SMI and less severe substance use attain sustained remission [23,24].

There is a lack of studies on how persons with SMI experience abstaining from substance use. However, research on substance use by clients without the comorbidity of mental illness indicates that social support is important to changing behaviour successfully $[25,26]$. Clients claim that they benefit from interventions that address their multiple recovery issues as opposed to ones that emphasize recovery strictly in sobriety terms [27]. Another qualitative study has noted the participants' view that highly structured programs and cognitive behavioural techniques are crucial to achieving abstinence [28]. As well as being a lifelong struggle for many clients, sobriety is perceived as a challenging state because of the risk that the person becomes 
complacent after achieving sobriety [29]. This may indicate a need for substitute dependency to maintain the abstinence [30,31].

It is of interest to examine how individuals with a psychotic disorder experience quitting substance use and to investigate reported experiences of former abstinence periods by participants still using substances. Two qualitative studies with a primary focus on how persons with SMI experience abstaining from substance use have reported that clients view substance use as one of many sources of adversity over a troubled life course [32] and that social support is critical to staying clean [33]. One ethnographic study of clients' perspectives showed that giving up substances was seen as a source of both pleasure and pain, and presupposed a certain level of rationality [34].

Some mixed-methods studies have reported on specific issues such as decision-making [35], reasons and strategies for quitting [21] and consequences of abstaining from substances [36]. One ethnographic study [37] and one self-reported study [38] have examined participants' reasons for quitting and have shown that supportive networks are influential in encouraging sobriety. Findings from studies using various research designs have indicated that meaningful activities and a safe living environment are important to abstinence from substance use in individuals with SMI [33,39,40]. In a 2010 study of patients' perspectives on their reasons for cannabis use, Asher and Gask [41] identified five reasons to abstain: disliking the effect and illegality of cannabis, financial benefits of abstaining, negative impact on physical and mental health, increased family support and hoping to develop relationships, and hopes for improved occupational and accommodation status.

Among persons diagnosed with SMI, more research has been published on reasons for substance use than on reasons for abstaining. Information relating to the latter may contribute to a better understanding of how individuals with SMI experience the efforts of abstaining. It is important to learn about the choices and efforts to quit substance use, especially among individuals with considerable vulnerability to substances such as those with SMI. The aim of this explorative study was to examine experiences of abstaining from substances of persons diagnosed with SMI. This included the reasons given as well as the requirements and strategies used for abstaining.

\section{Methods}

The study design was descriptive and explorative, and used a qualitative approach that aimed to examine the participants' experiences of abstaining from substances. A purposeful and criterionbased sampling procedure [42] was considered appropriate for our study. We collected cases rich with information, from which we could learn about issues of central importance to the purpose of the study. Our intention was to maximize the advantages of in-depth, purposeful sampling to lessen the influence of a small sample size. To provide sufficient time for each individual to provide the necessary in-depth information, we chose to perform individual semi-structured interviews with a focus on each participant's life world [43]. Transcriptions of the interviews were analysed using systematic text condensation [44], a stepwise procedure influenced by phenomenological psychology [45] that is well suited to examine lifeworld experiences.

\section{Recruitment and setting}

Eleven patients from five different assertive community treatment (ACT) teams throughout Norway were recruited to the study. Contact was first established by telephone with the team leaders of the five teams that had the most experience as ACT teams and that had included the most patients. Descriptions of the inclusion criteria and the purpose and procedures for the study were sent to the team leaders. After discussions within each team to identify potential candidates, the team leaders made appointments for interviews with those who agreed to participate. The inclusion criteria were persons with concomitant substance use and SMI treated in ACT teams who, after a minimum of 12 months of treatment, had made progress according to the patient and the team in terms of their quality of life and/or general functioning and/or substance use. The team leaders recruited the participants by consulting the rest of the team to determine whether they had patients who met the inclusion criteria for the study and whether both were willing and able to go through interviews. If a participant was in bad shape at the actual time of the interview, we agreed with the team leader and the participant to conduct the interview with a therapist attending. The team leaders also made appointments for the interviews. We do not know exactly how many patients were asked to participate or how many refused to take part in the study. However, our impression was that most of those asked agreed to participate. Two of the teams that did not contribute participants to the study had recruited three more patients, but they were not included because the sample size was already sufficient.

\section{Participants}

Eleven participants (nine men and two women), aged 27-63 years (mean 39 years), were included in the study. The duration of treatment in ACT was 14-30 months (mean 22 months) at the time of the first interview. Most had a diagnosis of schizophrenia or schizoaffective disorder, but persons diagnosed with bipolar disorder or an unspecified psychotic disorder also participated. For most participants, SMI had preceded their substance use.

Substances used were mainly cannabis and amphetamine and, to a lesser extent, alcohol and prescription drugs. Most of them used a combination of substances. Few seemed to use substances on a daily basis. Most typical use was 3-4 times a week, often in connection with lapses in their mental illness. Four of the participants were abstaining from substance use at the time of the study. Their abstinence periods ranged from 3 to 18 months (mean 10 months). Seven of the participants were still using substances at the time of the first interview. By the second interview, the abstainers were still abstinent and the users had continued their use. The abstaining group and the group of users did not differ significantly in their psychiatric diagnosis or history of substance use. The 11 participants shared their experiences of shorter and longer periods of abstaining from substances. Some of them talked of their abstaining periods retrospectively, and some were abstaining at the time of the interview.

\section{Interviews and data collection}

A thematic interview guide was used to organize the interview. This guide comprised issues relevant to the aim of the study. All 11 participants were asked to consider their former or present experiences of abstaining from substance use. The following themes were applied: 1) experiences of abstaining from substance use; 2) managing abstaining from substance use; and 3) influences of 
abstaining from substances on the participants' mental illness. Probing questions were used to explore further the issues raised.

The interviews were conducted by the first author predominantly on a one-to-one basis in a suitable meeting room provided by the ACT team. Two participants were accompanied by their therapist for safety or support reasons. Nine participants were interviewed twice, with 5-8 months between the interviews. Four months had lapsed between the last interview of the first set of interviews and the first interview of the second set of interviews. One participant did not agree to a second interview, and another was not accessible because of severe relapse of mental illness. The intention was to let the participants reflect freely on their experiences and to ask clarifying questions without making interpretations. The interviews lasted from 45 to 75 minutes, and all but one were recorded digitally and transcribed verbatim. For most interviews, the transcription was completed before the next interview. The reasons for a second interview were to explore important issues not covered during the first encounter, to provide the opportunity to examine specific topics more thoroughly and to clarify information given in the first interview. The latter was made possible by letting the participants read a transcript summary from the first interview or by providing a summary to the participants of the main points from transcriptions of the first interview. Reporting to participants what they had said in a previous interview can elicit better data [46]. Several of the participants reported on fundamental changes in their mental state and general functioning between the interviews-some for the better and others for the worse. This emerged in both the abstaining group and in the active users. None of the participants reconsidered or contradicted what he/she had told during the first interview.

\section{Analysis}

Systematic text condensation is a pragmatic approach for analysing qualitative data. This method is recommended for descriptive and explorative analyses of a phenomenon in reports from different participants and in developing new descriptions of a phenomenon $[44,45,47]$. Initially, the interview transcripts were read through to search for expressions viewed as important contributors to improvement. A total of 115 expressions (initial codes) were identified. Further searches for familiarity and diversity among the initial codes resulted in six overarching themes covering the whole data set. The main theme, Different aspects of substance use, was selected for analysis and covered all of the expressions from the participants concerning substance use. Because of the large number of meaning units within this main theme, it was split into Substance use as a coping strategy and Experiences of abstaining from substance use. The latter theme was selected for further analysis. A total of 27 meaning units, comprising sentences or paragraphs from the transcripts, were identified. These expressions covered both successful and unsuccessful efforts to abstain from substance use. The meaning units were organized into five sub-themes, and a text of condensed meaning was constructed for each one. The final stage comprised summarizing the meaning of the content into a new description. The analytic procedure is described elsewhere [48].

The first author was trained as a clinical nurse and has a master's degree in health promotion, and focused on factors influencing improvements and well-being. The interview transcripts were read with an open mind as a means to bracket the researcher's preconceptions and to focus on what the participants conveyed. In addition to the first author, who performed the data collection and most of the analysis, both the co-authors, AL and ER, contributed in two working sessions by identifying the initial codes and in the later theme development. TR contributed to several revisions of the manuscript. The software program NVivo 10 was used to output all codes to the worksheets, to manage all data and to confirm that no overlapping of data existed within each subtheme.

\section{Ethical considerations}

The interviews were conducted in the offices of the ACT team or accompanied by a therapist, and this served as a safeguard in the sense that the interviews could elicit emotional reminiscing about sensitive areas. Allowing the team leaders to receive a written or verbal report on the progress of each interview had the same purpose. It was important to emphasize that the intention of the interviews was research and not treatment. Pseudonyms are used to secure anonymity when citing the participants in this article. The study was approved by the Regional Committee for Medical and Health Research Ethics, South-East Region (no. 1196, 2010) before patients were included. Each participant gave their written, informed consent to take part in the study and was informed that he/she could withdraw from the study at any stage.

\section{Results}

The aim of this explorative study was to examine experiences of abstaining from substances of persons diagnosed with SMI. This included the reasons given as well as the requirements and strategies used for abstaining. From the analysis, two main thematic constellations were established. The first constellation dealt with individual factors, comprising the sub-themes influence on mental illness, emotional control and positive thinking. The second constellation dealt with structural factors and included the sub-themes relationships with people and places, activities and treatment.

\section{Individual factors}

The participants commented frequently about avoiding risky behaviour and handling their symptoms of mental illness. Experiences of control and positive thinking seemed essential to their being able to make rearrangements and to establish effective routines to achieve abstinence.

\section{Influence on mental illness}

When the participants referred to what influenced their mental illness, they focused mainly on motivation, obstacles and relationships, rather than how they experienced psychotic symptoms. Several expressions underscored substance use as a continuum of risky behaviour that can precipitate abstinence. Prominent was the fear of progression in the tolerance of substances and the transition to more heavy substance use; injecting heroin was considered the most dangerous. For most participants, moving from substance use to dependence seemed to symbolize a decline in their own view of themselves, and this seemed to contribute to quitting substance use. Ulrik had not quit his use of alcohol but had been through sober periods. His contemplations on substance use problems were illustrative:

Well, the best thing is to steer clear of it [alcohol], because if one has been drunk for several years, it then becomes a temptation. You have a tolerance level. That path starts with the small things and at the top is 
heroin. Hash is in the middle. So, the goal is not to start on that path at all.

The participants saw losing control of their substance use and becoming too intoxicated as a potential cause of a worsening of their illness. On the other hand, for several participants, the periods of abstinence were accompanied by feelings of shortcomings and fearful thoughts. It seemed that the lack of influence of substances released both positive and negative sensations.

Prominent among the still-active users was ambivalence about substance use. Earlier attempts to remain abstinent had not been an overall success for most. Jan, who was using mainly alcohol and some cannabis, articulated his former experiences of abstaining:

Once I stayed abstinent for one year. Being a chauffeur for my drinking friends, and things like that. I don't know what it is, but the anxiety developed. ... then the anxiety for the anxiety. I had Nozinan [levomepromazine] tablets as a remedy, but I chose to resume drinking.

Experiencing different symptoms of mental illness could be more challenging when abstaining from substance use. This challenge seemed to be dependent upon both the severity of the substance use and earlier experiences of abstaining and relapsing. All of the participants referred to episodes of abstaining, but most had not been heavy substance users. Most participants perceived that they had better overall functioning when they stayed away from substances.

\section{Emotional control and positive thinking}

Consistent with their unpleasant internal experiences of abstaining, the participants emphasized the importance of getting to know oneself. Some comments reflected the participants' experiences in becoming aware of both the boundaries to substance use and boundaries within oneself. They emphasized the ability to manage life without substances by practising positive thinking. Ulrik said:

I have to control my emotions, being nervous and being depressed; in other words, thoughts around my situation. It can be terrifying to manage, but it will be okay. I can manage it [abstinence], but not everyone can succeed if they are too negative.

The way one thinks about oneself reflects what other people think, and vice versa. How this thinking predominates was seen as a prerequisite to reaching sobriety and to being able to use legal substances in a normal manner. The importance of keeping going and remaining strong despite anxiety and depression was noted frequently. This was achieved mainly by controlling feelings and "keeping up" even if life is terrible at times. The rendering of time as a significant dimension in staying abstinent was also noted. Some comments underscored "getting high" as a step backward. Oliver thought retrospectively on his life and his former substance use, and tried to establish hope through imagining a future:

The substance use has dominated half of my life, but I think that if I live twice as long as I have until now, then it is just a quarter. So, if I manage to stay abstinent, the substance use will represent a smaller part of my life with every passing year.

Being able to quit after many years of substance use required being able to handle the craving. Some participants pointed to strategies to maintain control of challenging emotions. Oliver had established daily routines to counter the distress:
To manage the need to get high, I go to bed. After some time, when I wake up the next day, the need isn't the same. Just as long as I make it to the evening and go to bed, it gets a little easier every day.

Some of the expressed strategies were to avoid helplessness and find the motivation to quit. They stressed the importance of finding a "glimpse of light in life" and then following it. This was explained further as searching for meaning instead of the traditional escaping behaviour represented by substance use. Substance use represented an escape from some internal or external reality that they found difficult to live with (e.g., anxiety, depression, internal voices, isolation, loneliness, lack of confidence and boredom). A substance-free life was challenging because it required the use of other strategies.

\section{Structural factors}

Relational aspects were embedded in most of the reasons given and requirements for quitting substance use. Activities with mixed purposes and in different settings were often mentioned in association with relationships with other persons. Common reasons given as structural factors were not to forsake close relatives and friends, and being able to participate in daily life.

\section{Relationships with people and places}

Some of the expressed reasons for achieving abstinence emphasized the meaning of social relationships and avoiding isolation. The arguments were that one must be sober to find a partner and that being in a relationship decreases the need for substances. Remarks on the time dimension were also expressed in the context of quitting substance use. Many of those who were still active users did not see the need to become abstinent today, although in the long run, they tended to see their future as non-users or had a wish to achieve a more limited consumption of substances. For a large part, this imagination reflected the significance of a future spent living with a partner or in a stable family setting.

Oliver, one of the abstainers, looked forward to and contemplated factors important for his improvement:

The most important factor for my improvement is that I never had any good experiences, and I want to try to experience things better than I have. I hope I can calm down and have someone to hang around with. That's why I have to cut down on getting high, to try to focus on those goals.

Some participants reported that family members helped them quit substance use. Alice still used both hashish and amphetamine, and claimed the latter was posing the most problems:

I can manage a week ... or maximum two weeks without taking anything. But, then I get this urge ... I have been motivated to stay away from amphetamine for a while now. My parents also tried to motivate me ... so I managed almost two weeks abstinent. I thought that now I can have a fine time.

Staying abstinent was also motivated by not disappointing the people one is close to. One participant claimed that becoming a father for the first time motivated him greatly and that he felt an obligation not to forsake the enthusiastic professionals in the ACT team. Jamal had been abstinent for eight months by the second interview and reflected upon the impact of becoming a father:

I was focused completely on making the most out of my life, but then it was even more motivating hearing that I had a kid. You have 
to, if you want to be a good role model. You just think to yourself, "Are you a good role model for your kid if you get high every day?"

Another participant, Alice, also had children. However, she had chosen to continue her substance use. Her daughter lived with her father, but Alice managed to maintain contact with her daughter during short periods of abstinence, thereby protecting her from experiencing bad periods of Alice's illness or substance use. She had made the hard decision that the child's father was a better parent than she was. However, now she could at least regulate the substance use in accordance with important aspects of her life.

Some of the reasons given reflected the negative impact of the former life of belonging to a substance-using group. To avoid returning to old friends and substance use, it was important to actively oppose the influence of the old friends. Being somewhere in-between did not seem to work. Participants commented on the need to focus on remaining distant from physical and environmental factors prominent in the former substance-using way of life. Oliver referred to his experience of returning to his flat for his first period of leave from the institution:

I've refurnished the flat. It will be different to come home now, because I have experienced returning home on leave when it all reminded me of the old days and tempted me to take something [substances]. Last time, the thoughts didn't show up at all ... then it worked out much better.

Both people and places seemed to be highly related to habits formed by environments associated with substance use. Strategies involving some sort of detachment were the requirements expressed most often when envisioning a substance-free life. This seemed to include both supportive therapists and the ability of the person to develop a new way of thinking about or relating to people and places.

\section{Activities and treatment}

Taking part in daily living and doing ordinary activities were mentioned as contributors to quitting substance use. The significance of work and meaningful activities was expressed as a reason for abstaining, although some also expressed the view that staying away from substances could increase the possibility of becoming or remaining employed. Kent had been using amphetamine and cannabis but had been abstinent for the past year. He stated that his work and being able to drive a car were the main arguments for becoming sober:

I can't use anything. I will not be able to work then. You become ... you don't know how you will be the following day.

Physical training as one positive outcome of long-term treatment in hospital was also given as a reason to stop using substances. Being more satisfied with bodily appearance, having greater physical strength and participating in activities with others helped them handle the cravings. Odd reflected on his experiences:

The year I was hospitalized, I was introduced to weight training. There were a lot of activities, but most important was visiting the weight training centre two days a week. Now it's up to four days a week, but it all started in hospital. I feel more fit now. I guess it has contributed to me needing neither medicines nor alcohol.

Both activities initiated by others and self-imposed activities stimulated the participants to quit using or to reduce the need to take substances. Several statements underscored the importance of experiencing a more cheerful mood and being able to participate more in daily living while in the state of abstinence. Further implications were that a life of sobriety could lift people out of a life of isolation and loneliness through participation in activities. On the other hand, working towards sobriety and breaking contact with old friends also increased the feelings of being a loner.

The four abstainers saw both the ACT team and institutionalization as prerequisites to quitting substance use. This aspect seemed to be important regardless of whether the hospitalization was voluntary or by coercion. Jamal explained the process of being enrolled into treatment :

ACT enabled me to take the first step. I wouldn't dare on my own. The most important thing was that they got me into hospital and out of the flat. I realized I had problems, and I knew I had to do something.

Crucial factors of inpatient treatment seemed to comprise an established daily structure, non-availability of substances, physical activities and contact with peers. On the other hand, participants who were still users did not consider inpatient treatment important for their periods of abstinence. They focused more on the benefits of using a limited amount of substances rather than continuing with unsuccessful attempts to quit. ACT teams seemed to accept that sobriety was not a premise for participating in activities and that progress could be made despite the continued use of substances. Some comments indicated that reaching sobriety was a long-term objective.

\section{Discussion}

The aim of this explorative study was to examine experiences of abstaining from substances of persons diagnosed with SMI. This included the reasons given as well as the requirements and strategies used for abstaining. The analysis showed substantial impacts of social relationships and meaningful activities as reasons stated for quitting substance use. The importance of detachment towards people and places, positive thinking, controlling feelings and emotions, and fear of dependency were stated requirements and strategies used for abstaining.

Most participants in our study had not succeeded in abstaining from substance use. One possible explanation is that most had not been heavy substance users and did not use substances on a daily basis, and therefore had not experienced serious adverse effects from their use [48]. Other explanations could be that the duration of treatment in ACT was short and that the teams who recruited participants to our study were still in the developmental phase. The still-active users could be seen as being in a stage of precontemplation, according to the transtheoretical model of behaviour change (TTM). The main dimensions of TTM $[29,49,50]$ describe the five stages of change as precontemplation, contemplation, preparation, action and maintenance. To move from one stage to another, the individual must use processes of change, such as consciousness raising and self-reevaluation in the early stages, and conditioning, stimulus control and helping relationships in the later stages. A crucial factor in the change process, according to TTM, is the context of change, in the sense that no change occurs in a vacuum. Current life situation, beliefs and attitudes, interpersonal relationships, social systems and enduring personal characteristics can either facilitate or hinder successful behaviour change. In such a framework, the still-active users were more concerned about whether their substance use was a problem and to what extent their habits could be changed. Some of them had established substance-free periods and gave plausible arguments for 
their strategy. In a sense, they had moved from precontemplation to contemplation, and they seemed able to consider the advantages and disadvantages of their periods of substance use and abstaining. The abstainers were mainly in the action stage; i.e., abstinence had been reached but not firmly established.

Participants in our study clearly weighted the advantages against the disadvantages of using substances. On the one hand, substances were used to manage difficult emotional states, such as anxiety, depression, loneliness and boredom. Several self-report studies have identified persons with SMI to have mainly positive experiences with substance use, at least in a short-term perspective, and contingent upon not using substances too often or not using heavy substances [51]. Particularly the use of cannabis and amphetamine can make the hearing of inner voices experienced as less frightening, and contribute to clear up thought processes $[48,52,53]$. On the other hand, the stillactive substance users commented on their fear of developing dependency or becoming psychotic as arguments for having substance-free periods. Fear of dependency as a motivation for abstinence has not been mentioned in other studies, although some studies have noted the negative consequences of substance use as a motivation to quit $[21,54]$. Important to this finding is the difference in study samples: the latter studies included participants with overall more serious substance use compared with the participants in our study. This finding may indicate that lived experiences of substance use had led to an awareness that long- or short-term abstinence is needed to establish or maintain a stable life.

Remaining distant from the former adverse milieu of substance users was noted as a requirement and strategy for abstinence. This is consistent with the 2005 study by Davis and O'Neill [33], who identified five successful strategies for remaining abstinent: avoiding people, places and things; clinical and nonclinical support; meaningful activities; personal care and thinking differently. Their study included participants who were similar to those in our study except that their participants had an average time free of substance use of nearly three years. By contrast, other qualitative and self-report studies examining reasons to abstain did not emphasize the concept of avoidance $[21,32,41]$.

Some participants used the strategy of positive thinking to overcome problematic life events and stigma, and to establish abstinence. This strategy involved developing insight and goals to enable participants to handle troublesome thoughts without the influence of substances. This strategy was also identified in a qualitative study of relapse prevention in individuals diagnosed with SMI [33]. The concept of self-efficacy relates to self-regulation as one determinant of altering addictive behaviour and adhering to change over time [55]. The findings from our study partly contradict the basic conviction that individuals with SMI often exhibit cognitive impairment [5]. It seems that several participants in the present study had developed self-regulatory skills that enabled them to cope with the distress either through abstinence or by establishing substance-free periods.

Troublesome states of abstaining were more prevalent in our study than in similar research on individuals who had not been diagnosed with SMI [25-27]. This may indicate that individuals with comorbid SMI and substance use are more vulnerable while in the state of abstinence than are individuals without SMI. The literature supports such a hypothesis $[21,48,56]$. According to Drake et al. [20], one prominent risk factor for these individuals is the fluctuating nature of long-term mental illness. In a 2003 focus group study, Bradizza and
Stasiewicz [36] listed abstinence as one of 10 high-risk situations for individuals with SMI because of severe craving that may occur during abstinence. Our data indicate that it is not certain that pain can be eliminated by abstaining from substance use-at least from the shortterm perspective. It is also possible that a failure to achieve the expected improvement when abstaining from substance use creates frustration and disappointment in clients. As noted by Quimby [34], a certain amount of rational thinking is needed to forsake the pleasure in order to stop the pain. On the other hand, there is evidence that attaining abstinence reduces the negative outcomes of substance use in individuals with SMI [57-59]. Higher scores for social competence have been reported in abstainers in another study [39].

Many persons diagnosed with SMI are assumed to have low selfesteem because of the social stigma related to their psychiatric diagnosis $[60,61]$, which can be worsened by substance use $[5,62]$. Selfverification theory [63] may explain why some of the participants in our study experienced a worsening of their mental state after becoming abstinent. To quit substance use was viewed as a successful experience by both the participants and their therapists. However, consistent with the research evidence, participants with low selfesteem reported feelings of anxiety because success was experienced as surprising and unsettling [64]. Research has also found that participants with low self-esteem experience a worsening of general health over extended periods through the impact of positive life events $[65,66]$. Except for the 2003 study by Bradizza and Stasiewicz [36], we identified no relevant studies about how persons with SMI experience abstaining from substance use.

Several participants noted the importance of becoming sober to finding a partner and avoiding isolation. Care providers in the ACT were, to a certain degree, cited as agents who targeted both mental illness and substance use. By acting as mediators and referring participants to inpatient treatment, they were considered crucial to the users becoming aware of their problems. In this respect, the treatment setting seemed important; however, this finding contrasts with findings of other studies reporting that more people with substance use disorder recover without treatment than with treatment $[67,68]$.

Expressions of a gradual awareness that substance use conflicts with ordinary living and well-being were predominant in our study. Ethnographic research [37] and one self-report study [38] concluded that supportive networks are most important in helping individuals diagnosed with SMI to abstain from substance use. The 2012 explorative study by Henwood et al. [32] identified three events that contributed to quitting substance use: pivotal moments, maturation and institutionalization. The study by Henwood et al. was similar to our study except that most of the participants in their study were in long-term abstinence. Findings from our study support the significance of institutionalization for quitting substance use and, to a lesser degree, pivotal moments and maturation. The fact that the participants in our study did not specifically mention maturing out of substance use may be because most had not yet achieved long-term abstinence.

In a study of adolescents with mental illness and concomitant substance use, the participants reported an urge to use substances during periods of abstinence [69]. Establishing meaningful daily living and a supportive social network reduced the craving and thus enabled them to avoid substance use. Partly consistent with findings in the present study, the participants felt obliged to work continually to prevent relapse. They felt dependent upon supportive agents to manage their daily living while having troublesome thoughts. Some 
participants in the 2008 study by Thommesen [69] used a strategy of communicating with chosen individuals about their former substance use, which allowed them to receive support during the difficult times. In the present study, the participants noted that the members of the ACT team held a similar position through their extensive availability during the recruiting period to the ACT team, in day-to-day follow-up and during inpatient treatment.

The study was not intended to account for the experiences of all people with SMI and problematic substance use, but rather to examine this issue in some people. The results may shed light on the effects of similar treatment approaches in different cultural settings.

\section{Strengths and limitations}

Doing a second interview allowed the participants to read elements from the transcription of the first interview, and their feedback formed the basis of the subsequent theme development in the second interview. This also served as a way to enhance internal validation [47]. Giving the study participants feedback on their previous contribution can improve the quality of the data [46]. All of the participants in our study reported having a problematic use of substances when included into ACT, indicated by scores above cut-off on the screening instruments AUDIT and DUDIT. A minority of the participants in our study were abstinent at the time of the interviews, and had not been using heavy substances. This makes it difficult to compare our data with those of other studies of mainly people with severe substance use and experiences of long-term abstinence. Anyhow, all of them had former experiences of abstaining and thus contributed to the results of our study. Those participants who still used substances reported of abstaining periods in retrospect, and therefore the findings could be susceptible to bias. Furthermore, the use of a sample of clients in recovery, and thus not representative of the full range of clients with SMI enrolled in ACT, may limit the transferability of our results. On the other hand, to explore the experiences of abstaining from substance use as a subjective phenomenon involves focusing on the meaning the participants give to their substance use. This was an exploratory study, and the interpretation of the data should be considered within the context of qualitative research.

\section{Conclusions}

Our findings are mainly consistent with previous research on how individuals diagnosed with SMI experience abstaining from substance use. The data support the findings from other qualitative studies on the importance of social relationships and meaningful activities as reasons expressed for abstaining. The strategy of actively avoiding a former adverse milieu to reach sobriety has been reported in one other study, but the fear of adverse consequences, positive thinking and controlling feelings and emotions as described in the present study have not been reported in other qualitative studies. The data from this study should be confirmed by further explorative and qualitative research to investigate the reasons, requirements and strategies needed to quit substance use as expressed by both recovering and nonrecovering persons diagnosed with SMI. Furthermore it would be of interest to examine the perspectives of the treatment providers on this issue.

\section{Clinical implications}

Most individuals are capable of making informed choices about whether to continue substance use or to abstain. It is important that clinicians do not view abstinence from substance use as the only criterion of success and that they see the need for follow-up during phases of remission. It is crucial to consider the need for institutional treatment to address problematic substance use even in an assertive outreach setting. Psycho-educative approaches that address reality orientation and cognitive behavioural therapy to stimulate positive thinking should be available. Individuals with SMI and problematic use of substances should be offered family and network meetings, and should be encouraged to participate in meaningful activities and supported employment.

\section{Competing interests}

The authors declare that they have no competing interests.

\section{Acknowledgements}

We give special thanks to the study participants for their contribution to our research. The authors are grateful to Ingrid Amalia Havnes for important contributions to the data analyses and to Ricardo Lugo for assistance in translating the quotations from the interview transcripts.

\section{References:}

1. Kessler RC, Nelson CB, McGonagle KA, Edlund MJ, Frank RG, et al. (1996) The epidemiology of co-occurring addictive and mental disorders: implications for prevention and service utilization. Am J Orthopsychiatry 66: 17-31.

2. Hasin D, Kilcoyne B (2012) Comorbidity of psychiatric and substance use disorders in the United States: current issues and findings from the NESARC. Curr Opin Psychiatry 25: 165-171.

3. Morojele NK, Saban A, Seedat S (2012) Clinical presentations and diagnostic issues in dual diagnosis disorders. Curr Opin Psychiatry 25: 181-186.

4. Hartz SM, Pato CN, Medeiros H, Cavazos-Rehg P, Sobell JL, et al. (2014) Comorbidity of severe psychotic disorders with measures of substance use. JAMA Psychiatry 71: 248-254.

5. Mueser KT, Noordsy DL, Drake RE, Fox L (2003) Integrated treatment for dual disorders: A guide to effective practice. The Guilford Press, New York.

6. Padgett DK, Smith BT, Henwood BF, Tiderington E (2012) Life course adversity in the lives of formerly homeless persons with serious mental illness: context and meaning. Am J Orthopsychiatry 82: 421-430.

7. Lafeuille MH, Dean J, Fastenau J, Panish J, Olson W, et al. (2014) Burden of schizophrenia on selected comorbidity costs. Expert Rev Pharmacoecon Outcomes Res 14: 259-267.

8. Lehman AF, Myers CP, Corty E, Thompson J (1994) Severity of substance use disorders among psychiatric inpatients. J Nerv Ment Dis 182: 164-167.

9. Moggy F (2005) Etiological theories on the relationship of mental disorders and substance use disorders. Dual diagnosis: The evolving conceptual framework, Karger, Basel : 15-30.

10. Gonzalez VM, Bradizza CM, Vincent PC, Stasiewicz PR, Paas ND (2007) Do individuals with a severe mental illness experience greater alcohol and drug related problems? A test of the hypersensitivity hypothesis. Addict Behav 32: 477-490.

11. Atakan Z (2008) Cannabis use by people with severe mental illness - is it important? Adv Psychiatr Treat 14: 423-431. 
12. Koskinen J, Löhönen J, Koponen H, Isohanni M, Miettunen J (2010) Rate of cannabis use disorders in clinical samples of patients with schizophrenia: a meta-analysis. Schizophr Bull 36: 1115-1130.

13. Ringen PA, Melle I, Birkenaes AB, Engh JA, Faerden A, et al. (2008) Illicit drug use in patients with psychotic disorders compared with that in the general population: a cross-sectional study. Acta Psychiatr Scand 117: 133-138.

14. Latt N, Jurd S, Ternnant C, Lewis J, Macken L, et al. (2011) Alcohol and substance use by patients with psychosis presenting to an emergency department: changing patterns. Australas Psychiatry 19: 354-359.

15. Parakh P, Basu D (2013) Cannabis and psychosis: have we found the missing links? Asian J Psychiatr 6: 281-287.

16. Davis GP, Compton MT, Wang S, Levin FR, Blanco C (2013) Association between cannabis use, psychosis, and schizotypal personality disorder: Findings from the National Epidemiologic Survey on Alcohol and Related Conditions. Schizophr Res 151: 197-202.

17. Lechner WV, Dahne J, Chen KW, Pickover A, Richards JM, et al. (2013) The prevalence of substance use disorders and psychiatric disorders as a function of psychotic symptoms. Drug Alcohol Depend 131: 78-84.

18. Callaghan RC, Cunningham JK, Allebeck P, Arenovich T, Sajeev G, et al. (2012) Methamphetamine use and schizophrenia: a population-based cohort study in California. Am J Psychiatry 169: 389-396.

19. Potvin S, Stavro K, Pelletier J (2012) Paradoxical cognitive capacities in dual diagnosis schizophrenia. The quest for explanatory factors. J Dual Diagn 8: 35-47.

20. Drake RE, Wallach MA, McGovern MP (2005) Special section on relapse prevention. Future directions in preventing relapse to substance abuse among clients with severe mental illness. Psychiatr Serv 56: 1297-1302.

21. Laudet AB, Magura S, Vogel HS, Knight EL (2004) Perceived reasons for substance misuse among persons with a psychiatric disorder. Am J Orthopsychiatry 74: 365-375.

22. Landheim AS, Bakken K, Vaglum P (2006) Impact of comorbid psychiatric disorders on the outcome of substance abusers: a six year prospective follow-up in two Norwegian counties. BMC Psychiatry 6: 44.

23. Drake RE, McHugo GJ, Xie H, Fox M, Packard J, et al. (2006) Ten-year recovery outcomes for clients with co-occurring schizophrenia and substance use disorders. Schizophr Bull 32: 464-473.

24. McHugo GJ, Drake RE, Teague GB, Xie H (1999) Fidelity to assertive community treatment and client outcomes in the New Hampshire dual disorders study. Psychiatr Serv 50: 818-824.

25. Johansen AB, Brendryen H, Darnell FJ, Wennesland DK (2013) Practical support aids addiction recovery: the positive identity model of change. BMC Psychiatry 13: 201.

26. Orford J, Hodgson R, Copello A, John B, Smith M, et al. (2006) The clients' perspective on change during treatment for an alcohol problem: Qualitative analysis of follow-up interviews in the UK Alcohol Treatment Trial. Addiction 101: 60-68.

27. Vigilant L (2008) "I am still suffering": The dilemma of multiple recoveries in the lives of methadone maintenance patients. Sociol Spectrum 28: 278-298.

28. Lovejoy M, Rosenblum A, Magura S, Foote J, Handelsman L, et al. (1995) Patients' perspective on the process of change in substance abuse treatment. J Subst Abuse Treat 12: 269-282.

29. DiClemente CC (2006) Addiction and change: How addictions develop and addicted people recover. The Guilford Press, New York.

30. Morjaria A, Orford J (2002) The role of religion and spirituality in recovery from drink problems: A qualitative study of Alcoholics Anonymous members and South Asian men. Addict Res Theory 10: 225-256.

31. Vaillant GE (1988) What can long-term follow-up teach us about relapse and prevention of relapse in addiction? Br J Addict 83: 1147-1157.

32. Henwood BF, Padgett DK, Smith BT, Tiderington E (2012) Substance Abuse Recovery after Experiencing Homelessness and Mental Illness: Case Studies of Change Over Time. J Dual Diagn 8: 238-246.
33. Davis KE, O'Neill SJ (2005) A focus group analysis of relapse prevention strategies for persons with substance use and mental disorders. Psychiatr Serv 56: 1288-1291.

34. Quimby E (1995) Homeless clients' perspectives on recovery in the Washington, DC, Dual Diagnosis Project. Contemp Drug Prob 22: 265-289.

35. Childs HE, McCarthy-Jones S, Rowse G, Turpin G (2011) The journey through cannabis use: a qualitative study of the experiences of young adults with psychosis. J Nerv Ment Dis 199: 703-708.

36. Bradizza CM, Stasiewicz PR (2003) Qualitative analysis of high-risk drug and alcohol use situations among severely mentally ill substance abusers. Addict Behav 28: 157-169.

37. Alverson H, Alverson M, Drake RE (2001) Social patterns of substance use among people with dual diagnoses. Ment Health Serv Res 3: 3-14.

38. Gomez MB, Primm AB, Tzolova-Iontchev I, Perry W, Vu HT, et al. (2000) A description of precipitants of drug use among dually diagnosed patients with chronic mental illness. Community Ment Health J 36: 351-362.

39. Rollins AL, O'Neill SJ, Davis KE, Devitt TS (2005) Substance abuse relapse and factors associated with relapse in an inner-city sample of patients with dual diagnoses. Psychiatr Serv 56: 1274-1281.

40. Xie H, McHugo GJ, Fox MB, Drake RE (2005) Substance abuse relapse in a ten-year prospective follow-up of clients with mental and substance use disorders. Psychiatr Serv 56: 1282-1287.

41. Asher CJ, Gask L (2010) Reasons for illicit drug use in people with schizophrenia: Qualitative study. BMC Psychiatry 10: 94.

42. Patton MQ (2002) Qualitative research \& evaluation methods. Sage Publications, London.

43. Kvale S, Brinkman S (2008) Interviews. Learning the craft of qualitative research interviewing. Sage Publications, Thousand Oaks.

44. Malterud K (2012) Systematic text condensation: a strategy for qualitative analysis. Scand J Public Health 40: 795-805.

45. Giorgi A (2009) The descriptive phenomenological method in psychology: A modified Husserlian approach. Duquesne University Press, Pittsburgh.

46. Miles MB, Huberman M, Saldaña J (2013) Qualitative data analysis: A methods sourcebook. Sage Publications, Thousand Oaks.

47. Malterud K (2001) Qualitative research: standards, challenges, and guidelines. Lancet 358: 483-488.

48. Pettersen H, Ruud T, Ravndal E, Landheim A (2013) Walking the fine line: self-reported reasons for substance use in persons with severe mental illness. Int J Qual Stud Health Well-being 8: 21968.

49. Connors GJ, DiClemente CC, Velasques MM, Donovan DM (2013) Substance abuse treatment and the stages of change: Selecting and planning interventions. The Guilford Press, New York.

50. Prochaska JO (2008) Decision making in the transtheoretical model of behavior change. Med Decis Making 28: 845-849.

51. Wagstaff C (2007) Towards understanding the self-perception of people with psychotic illness who use illicit substances and have a history of disengagement from mental health services: qualitative research. Int J Psychiatric Nursing Res 12: 1503-1520.

52. Costain WF (2008) The effects of cannabis abuse on the symptoms of schizophrenia: patient perspectives. Int J Ment Health Nurs 17: 227-235.

53. Francoeur N, Baker C (2010) Attraction to cannabis among men with schizophrenia: a phenomenological study. Can J Nurs Res 42: 132-149.

54. Charles V, Weaver T (2010) A qualitative study of illicit and nonprescribed drug use amongst people with psychotic disorders. J Ment Health 19: 99-106.

55. Bandura A (1997) Self-efficacy: The exercise of control, W. H. Freeman and Company, New York.

56. Phillips P, Johnson S (2001) How does drug and alcohol misuse develop among people with psychotic illness? A literature review. Soc Psychiatry Psychiatr Epidemiol 36: 269-276. 
Citation: Pettersen H, Ruud T, Ravndal E, Landheim A (2014) Searching for Sobriety: How Persons with Severe Mental Illness Experience Abstaining from Substance Use. J Addict Res Ther 5: 193. doi:10.4172/2155-6105.1000193

Page 9 of 9

57. Bartels SJ, Teague GB, Drake RE, Clark RE, Bush PW, et al. (1993) Substance abuse in schizophrenia: service utilization and costs. J Nerv Ment Dis 181: 227-232.

58. Gonzalez G, Rosenheck RA (2002) Outcomes and service use among homeless persons with serious mental illness and substance abuse. Psychiatr Serv 53: 437-446.

59. Zisook S, Heaton R, Moranville J, Kuck J, Jernigan T, et al. (1992) Past substance abuse and clinical course of schizophrenia. Am J Psychiatry 149: 552-553.

60. Corrigan PW, Penn DL (1999) Lessons from social psychology on discrediting psychiatric stigma. Am Psychol 54: 765-776.

61. Lecomte T, Cyr M, Lesage AD, Wilde J, Leclerc C, et al. (1999) Efficacy of a self-esteem module in the empowerment of individuals with schizophrenia. J Nerv Ment Dis 187: 406-413.

62. Laudet AB, Magura S, Vogel HS, Knight E (2000) Support, mutual aid and recovery from dual diagnosis. Community Ment Health J 36: 457-476.

63. Swann WB Jr., Rentfrow PJ, Guinn JS (2005) Self-verification: The search for coherence: Handbook of Self and Identity, The Guilford Press, New York : 367-383.
64. Wood JV, Heimpel SA, Newby-Clark IR, Ross M (2005) Snatching defeat from the jaws of victory: self-esteem differences in the experience and anticipation of success. J Pers Soc Psychol 89: 764-780.

65. Brown JD, McGill KL (1989) The cost of good fortune: when positive life events produce negative health consequences. J Pers Soc Psychol 57: 1103-1110.

66. Shimizu M, Pelham BW (2004) The unconscious cost of good fortune: implicit and explicit self-esteem, positive life events, and health. Health Psychol 23: 101-105.

67. Klingemann H, Sobell MB, Sobell LC (2010) Continuities and changes in self-change research. Addiction 105: 1510-1518.

68. O'Toole TP, Pollini RA, Ford DE, Bigelow G (2008) The health encounter as a treatable moment for homeless substance-using adults: The role of homelessness, health seeking behavior, readiness for behavior change and motivation for treatment. Addict Behav 33: 1239-1243.

69. Thommesen H (2008) Hverdagsliv, selvforståelse og dobbeltdiagnose om mennesker med uvanlige erfaringer. Doktoravhandling, Høgskolen i Bodø. (Daily life, self-realization and dual diagnosis - about individuals with extraordinary experiences. Doctoral dissertation, University of Bodø) (in Norwegian). 